WTERFFAEF TECNOLOGGCA

\title{
ANÁLISE DE MERCADO DO ÓLEO DE ABACATE
}

\author{
AVOCADO OIL MARKET ANALYSIS \\ Juliana Aguiar - jujulianaguiar@hotmail.com \\ Marcos Alberto Claudio Pandolfi - marcos.pandolfi@fatectq.edu.br \\ Lucas Torquato Estracine - lucasestracine@hotmail.com \\ Faculdade de Tecnologia de Taquaritinga (Fatec) - Taquaritinga - São Paulo - Brasil
}

DOI: 10.31510/infa.v17i1.759

\section{RESUMO}

O abacate é originário da América Central e do México, muito utilizado na culinária. No Brasil o consumo da fruta é grande, principalmente in natura, doces e cada vez mais através do azeite (óleo extraído do fruto). O Brasil é um forte produtor de abacate, tendo o fruto plantado praticamente em todo o território. O azeite extraído da polpa do abacate é um dos mais nutritivos do mundo. As maiores áreas destinadas à produção de abacate são o Estado de São Paulo, Minas Gerais e Paraná. Atualmente este óleo possui alto valor comercial devido à pequena produção mundial. Há uma grande produção de abacate no país, porém a maior parte das vendas é do fruto in natura, ou seja, sem sofrer nenhum processo de transformação. São poucas indústrias brasileiras que também extraem o óleo de abacate. Esse óleo, além de ser consumido como alimento tem sido muito utilizado para fins cosméticos e no tratamento de problemas de pele como dermatites, inflamações e queimaduras. O objetivo do artigo é avaliar a viabilidade econômica das técnicas e da produtividade de extração de óleo de abacate, analisando o mercado concorrencial, fornecedor e consumidor.

Palavras-chave: Viabilidade. Abacate. Óleo. Extração.

\begin{abstract}
Avocado originates from Central America and Mexico, widely used in cooking. In Brazil, the consumption of fruits is large, especially in nature, sweets and increasingly through the oil extracted from the fruit. Brazil is a strong avocado producer, having the fruit planted practically throughout the territory. Olive oil extracted from avocado pulp is one of the most nutritious in the world. The largest areas selected for avocado production are the State of Sao Paulo, Minas Gerais and Paraná. Currently this oil has high commercial value due to the small world production. There is a large avocado production in the country, but most sales are fresh fruit, without undergoing any transformation process. There are few Brazilian industries that also extract avocado oil. This oil, besides being consumed as food, has been widely used for fine cosmetics and without treatment of skin problems such as dermatitis, inflammation and burns. The objective of the article is to evaluate the economic viability of the techniques and the use of avocado oil extraction, analyzing the competitive market, supplier and consumer.
\end{abstract}

Keywords: Viability. Avocado. Oil. Extraction 


\section{INTRODUÇÃO}

O abacate é uma das frutas mais comuns e mais consumidas pelos brasileiros e é produzida em todo o país. Devido sua alta produção no Brasil faz com que grande parte da população pense que o fruto é nativo brasileiro, porém é originário da América Central e do México. O estado de Minas Gerais se destaca como o maior produtor do óleo no Brasil e São Paulo como maior produtor da fruta. As variedades mais comuns e produzidas são o Ouro Verde, Quintal, Geada, Fortuna, Breda, Margarida e o avocado Haas e Fuerte. (SILVA, 2019)

Ainda de acordo com Silva (2019), as variedades Breda, Margarida e o Haas produzem azeites de alto valor nutricional. O azeite extraído da polpa do abacate é um dos mais nutritivos do mundo, o mais conhecido para extração é o Haas, pouco conhecido entre os brasileiros, já que chegou ao Brasil na década de 1970, essa espécie é popular na Califórnia nos Estados Unidos.

O Abacateiro pertence à família Lauraceae, gênero Persea. Abacates são geralmente híbridos entre as espécies ou raças: Mexicana (Persea americana var. drymifolia), Antilhana (P.americana var. americana) e Guatemalteca (P. nubigena var. guatemalensis). As primeiras mudas de Abacate chegaram ao Brasil no ano de 1893, quando frutos e mudas provenientes da Guiana Francesa entraram no país. As mudas foram dadas a Dom João VI e plantadas no Jardim Botânico do Rio de Janeiro. (ABPA, 2019)

O site Abacates do Brasil (2019) cita que, são conhecidas mais de 500 variedades de Abacate. A sazonalidade de cada variedade de Abacate depende das condições climáticas e outros fatores que influenciam na produção mais tardia ou precoce. No Brasil os principais tipos são o Avocado (Hass), Breda, Fortuna, Geada, Margarida, Ouro Verde e Quintal.

As maiores áreas destinadas à produção de abacate estão no Estado de São Paulo, Minas Gerais e Paraná. Esses estados são responsáveis por $85,7 \%$ da produção brasileira. Segundo o Instituto de Economia Agrícola (2019), o Brasil produziu em 2017, 213 mil toneladas de abacate. A figura 1 apresenta as variedades de abacate mais comercializadas dentro do Brasil. 
Figura 1: Variedades de Abacate

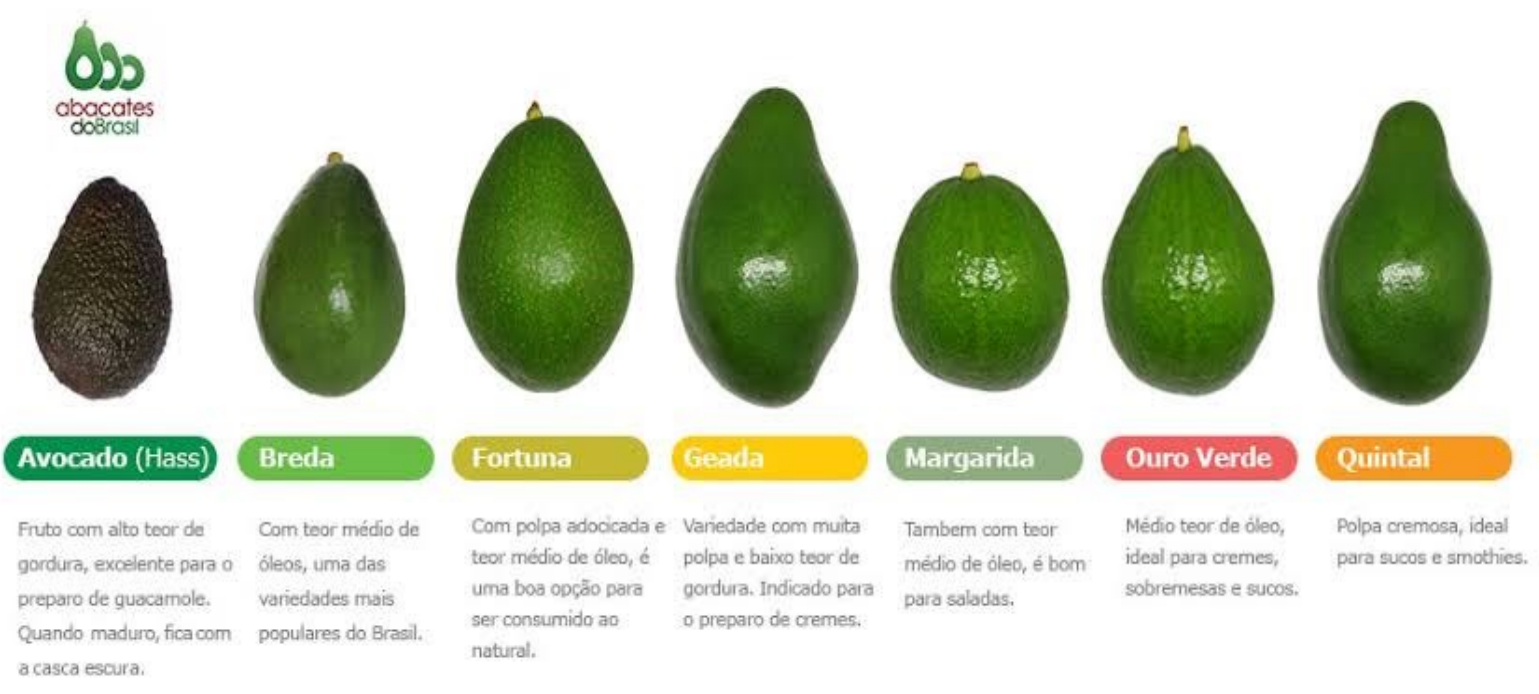

Fonte: Abacates do Brasil (2019)

O Óleo de Abacate tem sido muito utilizado para fins cosméticos, mostrando ser eficaz para deixar peles e cabelos saudáveis. É muito utilizado no tratamento de problemas de pele como dermatites, inflamações, queimaduras, acne e no pós-cirúrgico para acelerar a cicatrização, prevenindo a formação de marcas e queloides na pele. (TERUYA, 2014).

O óleo se destaca pelo seu excelente valor nutricional, é rico em B-sitosterol e ácido oleico, uma gordura insaturada utilizada como coadjuvante no tratamento de hiperlipidemias; uma das alternativas para oferecer ao consumidor brasileiro um produto de qualidade superior seria a produção de óleo de oliva e abacate mesclado, em substituição as misturas de óleo de oliva com óleos vegetais (principalmente óleo de soja), normalmente oferecidas pelo mercado interno com a finalidade de diminuir os custos de importação do azeite de oliva no Brasil (SOARES; MANCINI FILHO; DELLA MODESTA, 1998 apud SALGADO, 2008)

O objetivo do presente artigo é analisar o mercado nacional do óleo de abacate através de pesquisas sobre o mesmo, avaliar seus benefícios para a saúde, produção e os produtores do óleo no Brasil.

\section{FUNDAMENTAÇÃO TEÓRICA: EXTRAÇÃO DO ÓLEO}

O óleo de abacate bruto ou semi-refinado pode ser utilizado nas indústrias farmacêuticas e de cosméticos e o óleo refinado na indústria de cosméticos e na alimentação 


\section{WWTEPFAG TEECNOLOGGCA}

humana, como óleo para salada e para cozinha (TANGO e TURATTI, 1992 apud BUOSI; 2013).

Este óleo tem um rendimento por hectare cerca de 5 vezes maior que o da soja e 4 vezes maior que o do amendoim. Os custos de produção de abacate ficam em uma posição intermediaria entre os da soja e do amendoim. Alguns tipos de abacates possuem alto teor de matéria graxa. (BUOSI; 2013).

A proporção dos diferentes ácidos graxos no óleo de abacate pode ser influenciada pelo grau de maturação do fruto, pela localização da cultura e pelo clima dos diferentes campos agrícolas. (TANGO e TURATTI, 1992 apud BUOSI, 2013).

O consumo do azeite de abacate vem crescendo muito, principalmente entre os praticantes de esportes, antes e depois das práticas esportivas por favorecer a reposição de sais minerais. $\mathrm{O}$ abacate é consumido in natura, em pratos e como azeite. Possui aminoácidos em sua composição, com substâncias em combinação torna-se um bom antioxidante. Ajuda a balancear as taxas de colesterol, protege o coração, é um ótimo aliado no combate a doenças como o diabetes e alguns tipos de câncer e ainda possui 11 vitaminas e 14 minerais. (SILVA, 2019).

Segundo Silva (2019), o azeite de abacate possui muitos benefícios como, por exemplo: A saúde da pele e do cabelo; prevenção contra o câncer; saúde cardiovascular; redução da pressão arterial; saúde ocular e oral; redução de inflamações; perda de peso; absorção de nutrientes; controle da diabetes; fortalece o sistema imunológico; controla o colesterol; proteção da próstata; prevenção e tratamento de sinais de envelhecimento.

\section{PROCEDIMENTOS METODOLÓGICOS}

Para elaboração do presente artigo, foram feitas pesquisas bibliográficas através das referências teóricas já analisadas e publicadas por meio de sites, revistas, jornais, reportagens e artigo científicos.

Segundo Gil (2007, p. 44), os exemplos mais característicos desse tipo de pesquisa são sobre investigações e ideologias ou aquelas que se propõem à análise das diversas posições acerca de um problema. 


\section{RESULTADOS}

A época de colheita influencia os frutos, se colhidos 30 dias antes da época considerada normal para a colheita possuem maiores proporções de casca e caroço e menor porcentagem de polpa e apresentam também menores porcentagens de matéria graxa e teores mais elevados de agua na polpa. O teor de óleo do abacate está concentrado na polpa e, sendo esta a principal componente da fruta (SALGADO, 2008). A tabela 1 ilustra as variedades de abacate e respectivas épocas de maturação dos frutos da coleção de germoplasma do Centro de Fruticultura - Núcleo Experimental de Campinas - IAC, Campinas, SP, 1990.

Tabela 1: Épocas de maturação do fruto

\begin{tabular}{|c|c|c|c|}
\hline VARIEDADES & ÉPOCA DE COLHEITA & VARIEDADES & ÉPOCA DE COLHEITA \\
\hline Pollock & Janeiro - Março & Fuerte & Julho - Agosto \\
\hline Barker & Fevereiro - Março & Glória & Julho - Agosto \\
\hline Simmonds & Fevereiro - Março & Hass & Julho - Setembro \\
\hline Waldin & Março - Abril & Mac Donald & Julho - Setembro \\
\hline Vitória & Abril - Maio & Winslow & Agosto - Setembro \\
\hline Quintal & Maio - Junho & Itzamna & Agosto-Outubro \\
\hline Westin & Maio - Junho & Carlsbad & Setembro - Outubro \\
\hline Collinson & Maio - Julho & Mayapan & Setembro - Outubro \\
\hline Fortuna & Maio - Julho & Monte d'Este & Setembro - Outubro \\
\hline Winslowson & Junho - Julho & Sinaloa & Setembro - Outubro \\
\hline Linda & Junho - Agosto & Wagner & Setembro - Outubro \\
\hline Anaheim & Julho - Agosto & Ouro Verde & Setembro - Novembro \\
\hline
\end{tabular}

Fonte:Revista Brasileira de Fruticultura, 2004

O Óleo de Abacate é extraído quando os frutos estão maduros, ou seja, com consistência mole que é quando apresentam teores mais elevados de óleo. O principal obstáculo para obtenção do óleo é o alto teor de umidade que afeta o rendimento da extração, a qualidade do óleo e interfere no custo de produção. (MAPRIC, 2019).

O site Engenharia das Essências (2019) cita que este óleo possui alto valor comercial devido à pequena produção mundial. Apresenta-se como um óleo de cor variando do amarelo esverdeado ao avermelhado, com odor característico. Após o refino obtém-se um óleo amarelo claro, transparente e praticamente inodoro. $\mathrm{O}$ fruto do abacateiro possui teor de óleo que varia de 5 a $35 \%$.

Em 2017 o Brasil produziu 213 mil ton. de abacate e grande parte da comercialização foi interna (97,9\%). Os principais estados produtores da fruta são: São Paulo (121.216 ton.), Minas Gerais (50.751 ton.), Paraná (20.003 ton.), Rio Grande do Sul (4.520 ton.) e Distrito Federal (3.050 ton.), respectivamente. O valor da produção gerado pelo abacate no Brasil em 2017 foi de R\$245,6 milhões. O valor do abacate em São Paulo nos últimos anos apresentou 
um crescimento de aproximadamente 10,5\%. (BAPTISTELLA, 2019). O quadro 1 apresenta as áreas destinadas à colheita por hectare do ano de 2010 a 2016.

\section{Quadro 1: Área Destinada à Colheita (Hectares)}

\begin{tabular}{|c|c|c|c|c|c|c|c|}
\hline \multicolumn{8}{|c|}{ Produto das lavouras permanentes - Abacate } \\
\hline \multirow{2}{*}{ Brasil } & \multicolumn{7}{|c|}{ Ano } \\
\hline & 2010 & 2011 & 2012 & 2013 & 2014 & 2015 & 2016 \\
\hline Acre & 129 & 162 & 166 & 135 & 122 & 115 & 112 \\
\hline Amazonas & 203 & 198 & 92 & 59 & 33 & 317 & 57 \\
\hline Bahia & 15 & 15 & 12 & 72 & 90 & 50 & 239 \\
\hline Ceará & 484 & 477 & 480 & 483 & 498 & 453 & 456 \\
\hline Distrito Federal & 111 & - & 295 & 160 & 134 & 154 & 153 \\
\hline Espírito Santo & 277 & 14 & 263 & 276 & 300 & 319 & 345 \\
\hline Goiás & 32 & 67 & 57 & 20 & 26 & 52 & 71 \\
\hline Minas Gerais & 2202 & 2134 & 2309 & 2416 & 2373 & 2925 & 2924 \\
\hline Pará & 22 & 22 & 22 & 22 & 22 & 26 & 17 \\
\hline Paraíba & 89 & 91 & 89 & 89 & 86 & 81 & 70 \\
\hline Paraná & 1000 & 944 & 922 & 958 & 930 & 929 & 1000 \\
\hline Pernambuco & 310 & 308 & 86 & 48 & 48 & 37 & 37 \\
\hline Rio de Janeiro & 36 & 36 & 34 & 28 & 23 & 28 & 30 \\
\hline Rio Grande do Nor & 92 & 94 & 89 & 91 & 94 & 185 & 45 \\
\hline Rio Grande do Sul & 575 & 552 & 499 & 470 & 444 & 405 & 393 \\
\hline Santa Catarina & 6 & 6 & 4 & 4 & 4 & 4 & 4 \\
\hline São Paulo & 5530 & 5642 & 4192 & 4374 & 4337 & 4301 & 4915 \\
\hline
\end{tabular}

Fonte: IBGE (2016) - Produção Agrícola Municipal

Como observado no quadro 1, o total da área destinada à colheita no ano de 2016 somando todos os estados foi de 10.868 hectares, abaixo veremos a tabela de 2017 e 2018 , no qual notamos um grande crescimento dessa área, os valores já serão vistos no geral. O quadro 2 apresenta a área total destinada à colheita de abacate no Brasil.

Quadro 2: Área Destinada à colheita (hectares)

\begin{tabular}{|c|c|}
\hline Variável - Área destinada à colheita (Hectares) \\
\hline \multicolumn{2}{|c|}{ Brasil } \\
\hline \multicolumn{2}{|c|}{ Produto das lavouras permanentes - Abacate } \\
\hline 2017 & 2018 \\
\hline \multicolumn{2}{|c|}{ Ano } \\
\hline \multicolumn{2}{|c|}{14.356} \\
\hline Fonte: IBGE - Produção Agrícola Municipal \\
\hline
\end{tabular}

Fonte: IBGE 2017

Interface Tecnológica - v. 17 n. 1 (2020) 


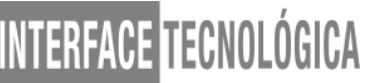

De acordo com o IBGE (2017), podemos notar em seguida no quadro 3 que o Brasil tem crescido significativamente na quantidade produzida de abacate, seu rendimento de produção no ano de 2016 era de 196.545 e em 2018 foi para 235.788

Quadro 3: Quantidade Produzida

\begin{tabular}{|c|c|c|}
\hline \multicolumn{2}{|c|}{ Variável - Quantidade produzida (Toneladas) } \\
\hline \multicolumn{2}{|c|}{ Brasil } \\
\hline \multicolumn{3}{|c|}{ Produto das lavouras permanentes - Abacate } \\
\hline 2016 & 2017 & 2018 \\
\hline 196.545 & 212.873 & 235.788 \\
\hline \multicolumn{2}{|c|}{ Ano } \\
\hline \multicolumn{2}{|c|}{ Fonte: IBGE - Produção Agrícola Municipal } \\
\hline
\end{tabular}

Fonte: IBGE 2017

O valor da produção também cresceu e isso ocorreu devido à alta demanda pela fruta, e nos próximos anos, pode-se notar que esses valores vão aumentar conforme o seu consumo no pais. O quadro 4 apresenta a evolução do valor de produção de 2016 a 2018.

Quadro 4: Valor da Produção

\begin{tabular}{|c|c|c|}
\hline \multicolumn{2}{|c|}{ Variável - Valor da produção (Mil Reais) } \\
\hline \multicolumn{3}{|c|}{ Brasil } \\
\hline \multicolumn{3}{|c|}{ Produto das lavouras permanentes - Abacate } \\
\hline 2016 & 2017 & 2018 \\
\hline 230.129 & Ano & 318.096 \\
\hline \multicolumn{2}{|c|}{247.546} & \\
\hline Fonte: IBGE - Produção Agrícola Municipal \\
\hline
\end{tabular}

Fonte: IBGE 2017

Observando o quadro 4 é possível verificar um aumento gradual nos 3 anos analisados. 


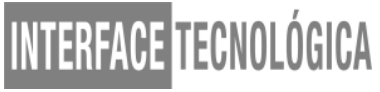

Na cidade de São Sebastião do Paraíso MG, no Sudoeste do Estado são produzidos os azeites de abacate das variedades Haas, Breda e Margarida. Cosméticos também são produzidos a base de abacate pela empresa Flor do Abacate que nasceu da visão do engenheiro agrônomo José Carlos Gonçalves, produtor de café nos estados de Minas Gerais e São Paulo, em parceria com seu filho Carlos Alberto Pinto Gonçalves, eles queriam aproveitar melhor a terra apostando em outra cultura. No ano 2019 deu-se início à produção do azeite de Abacate Paraíso Verde. O azeite é extraído em maquinários modernos, a frio, sem nenhum

aditivo químico. É puro e muito saboroso. A produção do azeite coincide com a safra do abacate das lavouras brasileiras e estende-se durante todo o segundo semestre. (SILVA, 2019).

O proprietário da empresa Flor de Abacate Carlos Alberto Pinto Gonçalves, diz que investir na extração do óleo da "azeitona tropical" - chamado assim por ele considerar o óleo de abacate superior ao extraído da oliva - é o caminho para alcançar o sucesso na comercialização. Em 2014 em uma parceria com a Empresa de Pesquisa Agropecuária de Minas Gerais (Epamig), realizou a extração de 100 litros de óleo de abacate para testar o maquinário e posteriormente financiou estudos com o material junto as universidades, agregando resultado para o projeto, o projeto foi iniciado em 2015 e começou sua produção no segundo semestre de 2018 (FAEMG, 2015)

A empresa Flor do Abacate trouxe para o mercado uma nova visão de reaproveitamento e uso de um fruto há muito tempo conhecido, essa indústria tem como principal produto o óleo/ azeite de abacate; estão sendo estudados subprodutos como a farinha de abacate, que será feita através do aproveitamento do resíduo solido da extração do óleo e o inseticida que terá como base o caroço do abacate. Para a empresa o óleo de abacate tem dois fins: o primeiro que será usado como base para cosméticos e outros produtos farmacêuticos; e o segundo que o azeite de abacate pode ser consumido puro ou utilizado em diversos molhos, para tempero de salada, regar hortaliças e em pratos quentes. Comparado a outros óleos vegetais o óleo de abacate é bem estável a altas temperaturas. Em seguida na figura 2 teremos um dos produtos que a empresa produz. 


\section{WTEERFAEETECNOLOGGCA}

Figura 2: Azeite de Abacate

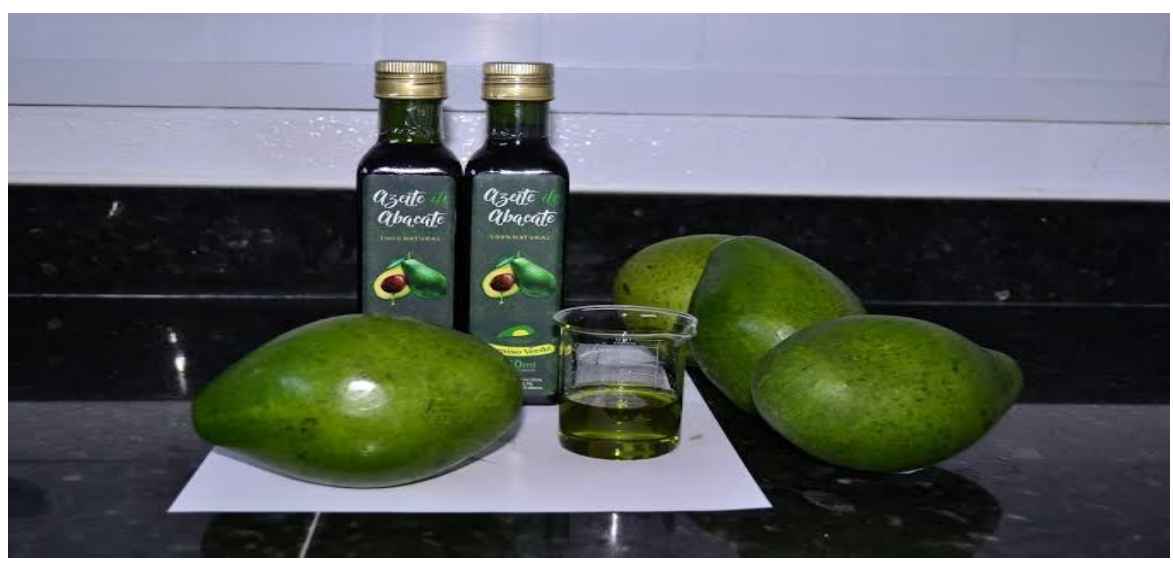

Fonte: Paraiso Verde (2019)

Segundo levantamento da Associação Brasileira de Redes de Farmácias e Drogarias (Abrafarma) apud. CB Economia, 2019, as 25 maiores varejistas do setor movimentaram R\$ 4,7 bilhões entre janeiro e março de 2019. O valor corresponde a um salto de $10,64 \%$ em relação ao mesmo período do ano de 2018.

De acordo com o SEBRAE, (2019) é necessário contratar um contador profissional para legalizar a empresa nos seguintes órgãos, Junta Comercial; Secretaria da Receita Federal (CNPJ); Secretaria Estadual de Fazenda; Registro no Ministério da Saúde; Prefeitura do Município para obter o alvará de funcionamento; Enquadramento na Entidade Sindical Patronal; Corpo de Bombeiros Militar e Alvará de Localização e Licenciamento Ambiental. Nos termos da Lei $\mathrm{n}^{0} 6938$ Art.17 incisos I e II é obrigatório o registro no Ibama de todas as pessoas físicas ou jurídicas que se dedicam a atividades potencialmente poluidoras e/ou a extração, produção, transporte e comercialização de produtos potencialmente perigosos ao meio ambiente, assim como de minerais, produtos e subprodutos da fauna e flora, indicadas na IN no 010/01. A empresa deve possuir registro ANVISA - Agência Nacional de Vigilância Sanitária.

\section{CONSIDERAÇÕES FINAIS}

O óleo de abacate é um produto completo que possui vitaminas, proteínas, ômegas que quando consumidos, são revertidos em benefícios ao organismo. Além do azeite destinado à alimentação, uma parte dele é encaminhada à produção de cosméticos muito especiais que possuem, em sua formulação, uma dose de óleo puro de abacate. (SILVA, 2019). 
O mercado e o plantio de abacate no Brasil se encontram em praticamente todo o território. Porém a produção do óleo de abacate não é uma prática comum no país. No mundo a produção de óleo a partir do abacate também não é de grande destaque. Por mais que não seja uma prática conhecida no país, o consumo de óleo de abacate está aumentando cada vez mais, trazendo benefícios ao consumidor, ao produtor e principalmente a indústria processadora, devido ao alto valor agregado.

Para a extração do óleo é necessário à aquisição de máquinas específicas para extração. O processo é muito similar ao do azeite de oliva. O Abacate para produção de óleo tem um rendimento por hectare cerca de 5 vezes maior que o da soja e 4 vezes maior que o do amendoim. Os custos de produção de abacate ficam entre os da soja e do amendoim. Para a extração do óleo se deve usar o abacate maduro, pois seu teor de óleo na polpa eleva-se.

É necessária a regularização da empresa que estiver interessada em processar e extrair o óleo e também a regularização do produto. As instalações devem ser adequadas e higiênicas para a extração do óleo. Boas condições de trabalho para o empregado e boas práticas de fabricação são essenciais para melhorias no processo e no produto. $\mathrm{O}$ bom dimensionamento e localização facilitam o processo e o fornecimento de matéria prima.

\section{REFERÊNCIAS}

ABACATES DO BRASIL; "Diferentes tipos de abacate - safras e receitas"; 2019 Disponível em: https://abacatesdobrasil.org.br/tipos-de-abacates-safras-e-receitas/ Acesso em: 04 de Mar. 2020

BAPTISTELLA, Celma Da Silva Lago; JOSÉ, Paulo; “O Abacate no Estado de São Paulo: 2009 a 2018”; IEA - INSTITUTO DE ECONOMIA AGRÍCOLA; São Paulo - SP; 2019 Disponível em: http://www.iea.sp.gov.br/out/TerTexto.php?codTexto=14581 Acesso em: 08 de Ago. 2019

DORSA, Renato; CARANTI, José; “Óleo de Abacate"; 2019 Disponível em: https://docplayer.com.br/67289093-Oleo-de-abacate-maiores-produtores-mundiais-deabacates-ton.html Acesso em 15 de Nov. 2019

ENGENHARIA DAS ESSÊNCIAS; “Óleo de Abacate Refinado"; 2019 Disponível em: https://engenhariadasessencias.com.br/loja/manteigas-oleos-vegetais/477-oleo-de-abacaterefinado.html Acesso em: 07 de Ago. 2019

GIL, A.C. Métodos e técnicas de pesquisa social. São Paulo: Atlas, 2007. Acesso em: 14 de Fev. 2020 


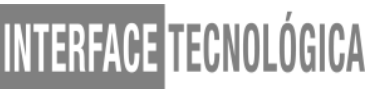

IBGE; “Censo Agropecuário", 2017 Disponível em: https://cidades.ibge.gov.br Acesso em: 15 de Ago. 2019.

IBGE; "Produção Agrícola Municipal: Área destinada a colheita, quantidade produzida, valor da produção"; 2017 Disponível em: https://sidra.ibge.gov.br/tabela/1613\#resultado Acesso em: 04 de Mar. 2020

MAPRIC; "Óleo de Abacate”; 2019 Disponível em:

https://mapric.com.br/pdf/Boletim917 29082014-18h00.pdf Acesso em: 09 de Ago. 2019

MARTINS, Tabata; "Mercado: crise do abacate"; Belo Horizonte - MG; 2019.

Disponível em https://www.foodservicenews.com.br/mercado-crise-do-abacate/Acesso em:

09 de Ago. 2019

SALGADO, Jocelem Mastrodi; DANIELI, Flávia; REGITANO-D'ARCE, Maria Aparecida Bismara; FRIAS, Andrea; MANSI, Débora Niero, "O óleo de abacate (Persea americana Mill) como matéria- prima para a indústria alimentícia", Faculdade de Engenharia de Alimentos, UNICAMP, Campinas - SP; 2008 Acesso em: 10 de Ago. 2019

SÃO FRANCISCO, Portal “Abacate: histórico”, Rio de Janeiro - RJ; 2019 Disponível em https://www.portalsaofrancisco.com.br/alimentos/abacate Acesso em: 09 de Ago. 2019

SEBRAE; "Fábrica de óleos naturais / essências"; 2019 Disponível em: http://www.sebrae.com.br/sites/PortalSebrae/ideias/como-montar-uma-fabrica-de-oleosnaturais-e-essencias,c2387a51b9105410VgnVCM1000003b74010aRCRD Acesso em: 08 de Ago. 2019

SILVA, Arnaldo; "Minas se destaca na produção de azeite de abacate", 2019 Disponível em: https://www.conhecaminas.com/2019/07/minas-se-destaca-na-producao-de-azeite.html Acesso em: 15 de Nov. 2019

SISTEMA FAEMG; “Óleo de abacate evita desperdício de frutos e diversificação da produção é aposta do produtor"; 2015 Disponível em:

http://www.sistemafaemg.org.br/Noticia.aspx?Code=9792\&ParentPath=None\&ConteVersion $=\mathrm{R}$ Acesso em: 05 de Mar. 2020

TANGO, João Shojiro; CARVALHO, Cassia Regina Limonta; SOARES, Nilberto Bernado; "Colheita e pós- colheita: Caracterização física e química de frutos de abacate visando a seu potencial para extração de óleo"; Revista Brasileira de Fruticultura; vol.26, no. 1, Jaboticabal, SP, 2004 Acesso em: 04 de Mar. 2020 